\title{
Intrapericardial foregut cyst associated with intrauterine death
}

\author{
E E Mooney, T D Wax, K A Reimer
}

\begin{abstract}
Intrapericardial developmental foregut cysts are rare and are most frequently incidental findings at necropsy in adults. A 29 year old Asian woman delivered a 24 week stillborn fetus seven days after diagnosis of intrauterine death caused by rupture of a foregut cyst. Multiple cysts occupied the wall of the right atrium and its rupture caused haemopericardium and cardiac tamponade.

(f Clin Pathol 1997;50:962-963)
\end{abstract}

Keywords: fetal death; haemopericardium; foregut cyst

Department of

Pathology, Duke

University Medical

Center, Durham,

North Carolina, USA

E E Mooney

K A Reimer

Department of

Pathology, Cabarrus

Memorial Hospital,

Concord, North

Carolina, USA

T D Wax

Correspondence to:

Dr Reimer, Department of Pathology, Box 3712, Duke University Medical Center, Durham, NC 27710, USA

Accepted for publication 15 July 1997

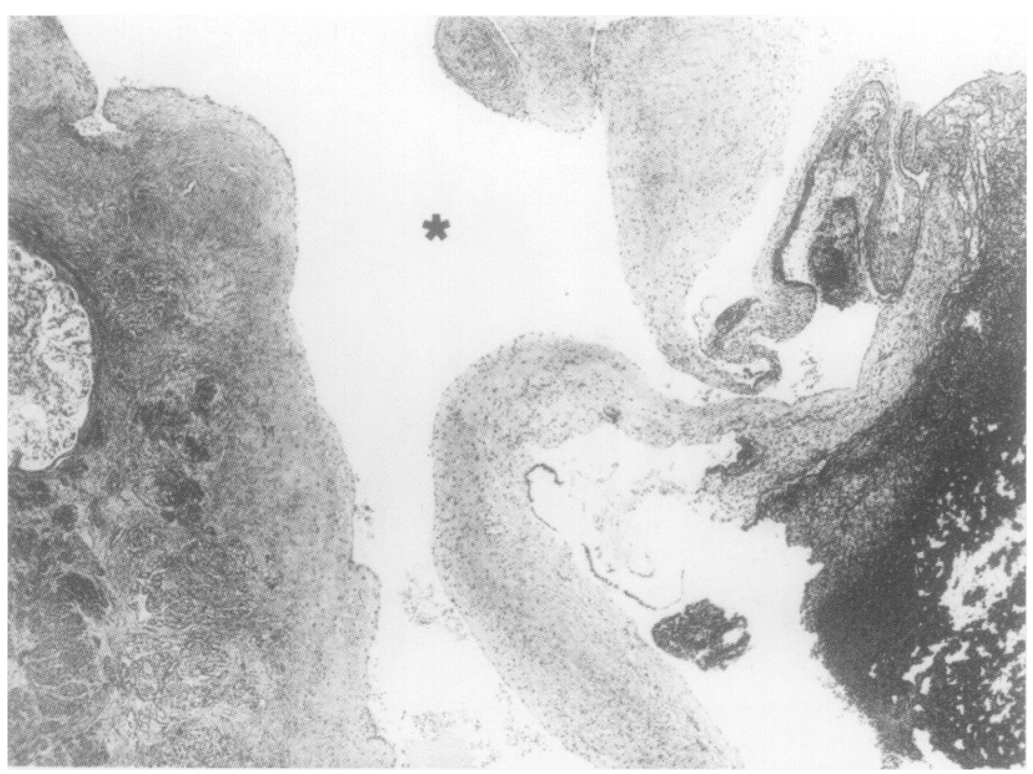

Figure 1 Right atrium, with lumen (asterisk) and thinned wall that has ruptured (centre right). Pericardial haematoma is shown on the right, and an intact cyst in the atrial wall on the left of the picture (haematoxylin and eosin; original magnification $\times 25$ ).

A 29 year old Asian woman (gravida 3, para 3) after diagnosis of intrauterine death. The pregnancy was complicated by gestational diabetes mellitus and hypothyroidism. The fetus was normally developed, weighed $513 \mathrm{~g}$, with a crown-rump length of $23 \mathrm{~cm} .^{1}$ There was moderate maceration, but no external abnormalities were identified.

At necropsy, the pericardium was distended with $3 \mathrm{ml}$ of clotted blood, with a rupture site visible in the wall of the right atrium. There were no anomalies of the gross anatomy of the heart $(3.1 \mathrm{~g})$ or great vessels.

Microscopically, the atrial wall was of variable thickness, with recent and organising haematoma at the rupture site (fig 1). Multiple cysts up to $3 \mathrm{~mm}$ in diameter were identified in the atrial wall. These were lined by a columnar epithelium that was ciliated (fig 2) and showed focal pseudostratification. No inflammatory infiltrate was present. The cysts contained cell debris that was partly calcified. Concentrically arranged smooth muscle, but no cartilage or seromucinous glands, was present beneath the epithelial lining. No neuroectodermal structures such as skin, skin appendages or neuronal tissue were identified. The atrial septum and ventricles were normal. The remainder of the necropsy was unremarkable and the placenta $(166 \mathrm{~g})$ showed changes consistent with intrauterine fetal death. Cytogenetic analysis performed on amniotic fluid following diagnosis of intrauterine fetal death showed a normal female karyotype (46, $\mathrm{XX}$ ). delivered a 24 week stillborn fetus seven days

\section{Discussion}

Developmental foregut cysts within the pericardium are rare, with approximately 35 cases reported. ${ }^{2}$ Although most frequently an incidental necropsy finding in adults, some cases have presented with symptoms of pericarditis. ${ }^{34}$ They are frequently described as intrapericardial bronchogenic cysts (IPBC) among other terms. ${ }^{2}$ One third of patients with such cysts are infants, who are almost always symptomatic with respiratory distress and cyanosis, the size and location of the cyst causing vascular compromise. ${ }^{56}$ IPBC are usually not associated with any cardiac anomalies. ${ }^{7}$ Microscopically, they should be distinguished from the more common teratomas that contain tissues of neuroectodermal derivation such as skin, teeth or glial tissue. As little distinction was made between IPBC and teratomas in the earlier literature on the subject, some of the deaths ascribed to cardiac teratoma may have been due to IPBC. ${ }^{8}$ For example, Jellen and Fisher ${ }^{9}$ reported a case of neonatal death secondary to what they called an intrapericardial teratoma, although the histology suggests that this may have been a bronchogenic cyst.

Cystic tumour of the atrioventricular node has a characteristic location, and as an endodermal derivative may also show ciliated epithelium. ${ }^{2}$ Ciliated epithelial cysts have been reported on the tricuspid valve ${ }^{10}$ and in the left ventricle. ${ }^{11}$ Despite the absence of other bronchial tissues such as cartilage, their histogenesis is similar. Before the obliteration of the dorsal mesocardium between the 7 th and 16th somatic stages, the foregut is in close proximity to the developing heart. ${ }^{12}$ Sequestration of foregut tissue may occur before fusion of the paired coelomic cavities that become the pericardium, and result in intrapericardial or intramyocardial cystic rests. Those in the myocardium are 


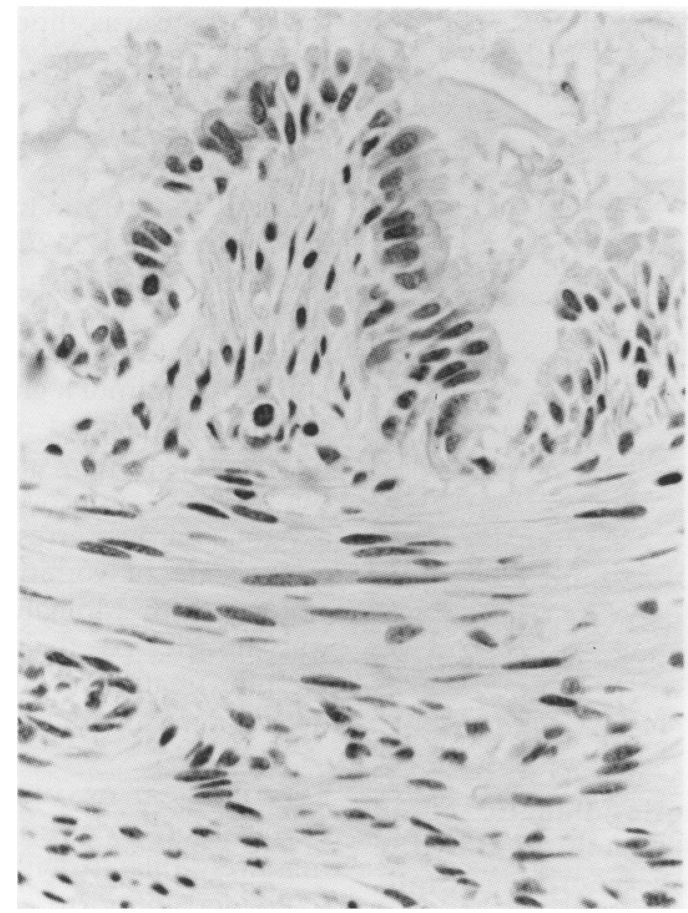

Figure 2 .Cyst wall showing ciliated columnar epithelium and circular smooth muscle (haematoxylin and eosin; original magnification $\times 520$ ).

typically located in the posterior wall of the left ventricle. ${ }^{11}$ Differences in timing of such misplacement probably account for the varying location and composition of foregut cysts.

Haemopericardium leading to intrauterine death is a rare event. Emboli from placental vessels causing acute myocardial infarction with resultant right ventricular rupture was described by Wolf et al. ${ }^{13}$ Other cases have followed a motor vehicle accident ${ }^{14}$ and amniocentesis. ${ }^{15}$ The case described here is unique in that it is the first in which an intrapericardial foregut cyst was the cause of intrauterine death. We have not been able to find an account of rupture of the heart secondary to this lesion, but given the histogenesis and frequent presentation in early childhood, it is not altogether surprising that a foregut cyst may cause intrauterine death.

1 Singer DB, Sung CJ, Wigglesworth JS. Fetal growth and maturation: with standards for body and organ development. In: Wigglesworth JS, Singer DB, eds Textbook of fetal and perinatal pathology. Boston: Blackwell 1991:11-48.

2 Burke AP, Virmani R. Tumors of the heart and great vessels. Burke AP, Virmani R. Tumors of the heart and great vessels.
Atlas of tumor pathology, 3rd series, Fascicle 16 . WashingAtlas of tumor pathology, 3rd series, Fascicle 16. Washington,

3 Gomes $\mathrm{MN}$, Hufnagel CA. Intrapericardial bronchogenic cysts. Am f Cardiol 1975;36:817-22.

4 Shimizu M, Takeda R, Mifune J-I, Tanaka T. Echocardiographic features of intrapericardial bronchogenic cyst. Cardiology 1990;77:322-6.

5 Deenadayalu RP, Tuuri D, Dewall RA, Johnson GF Intrapericardial teratoma and bronchogenic cyst. Review of literature and report of successful surgery in infant with intrapericardial teratoma. F Thorac Cardiovasc Surg 1974; 67;945-52.

6 Hayashi AH, McLean DR, Peliowski A, Tierney AJ, Finer NN. A rare intrapericardial mass in a neonate. $\mathcal{F}$ Pediatr Surg 1992;27:1361-3.

7 Thomas R, Van Wesep R. Intrapericardial epithelial cyst in association with an atrioventricular canal defect. Am f Car diovasc Pathol 1990;3:325-8.

8 Dabbs $\mathrm{CH}$, Berg R, Peirce EC. Intrapericardial bronchogenic cysts. Report of two cases and probable embryologic explanation. F Thorac Surg 1957;34:718-35.

9 Jellen J, Fisher WE. Intrapericardial teratoma. $A m \mathcal{F}$ is Child 1936;51:1397-402.

10 Machens G, Vahl CF, Hofmann R, Wolf D, Hagl S. Entodermal inclusion cyst of the tricuspid valve. Thorac Cardiovasc Surgeon 1991;39:296-8.

11 De Lacroix WF, Hubner G. Ciliated epithelial inclusion cyst of the heart. Beitr Pathol 1974;151:103-10.

12 Todd JL, Silverman ME, Kirby ML, Gray SW, Skandalakis JE. Heart. In: Skandalakis JE, Gray SW eds. Embryology for surgeons, 2nd edn. Baltimore: Williams and Wilkins, 1994 912-57.

13 Wolf PL, Jones KL, Longway SR, Benirschke K, Bloor C. Prenatal death from acute myocardial infarction and cardiac tamponade due to embolus from the placenta. $A m$ Heart f 1985;109:603-5.

14 Sherer DM, Abramowicz JS, Babowski R, Metlay LA, Ron $M$, Woods JR. Extensive fetal intrathoracic injuries sustained in a motor vehicle accident. Am 7 Perinatol 1993 10:414-16.

15 Berner HW, Seisler EP, Barlow J. Fetal cardiac tamponade. A complication of amniocentesis. Obstet Gynecol 1972;40: 599-604.
Departments of Histopathology and Medicine, Royal Hallamshire Hospital, Glossop Road, Sheffield S10 2JF, UK

Correspondence to: Dr Wight, Department of Histopathology, Nottingham City Hospital NHS Trust, Hucknall Road, Nottingham, NG5 1PB, UK.

Accepted for publication 2 September 1997

\section{Gastric outflow obstruction caused by gall stones and leading to death by complex metabolic derangement}

\author{
C O Wight, M Seed, W W Yeo, T A McCulloch
}

had an asystolic cardiac arrest the following day; she was transferred to the intensive care unit and despite treatment with inotropes she died 40 hours after admission. Necropsy revealed that the stomach was massively dilated with gas and stomach contents, and contained many small black faceted gall stones. In addition a large nonfaceted brown-yellow gall stone was wedged in the pyloric antrum causing total obstruction. The patient had died from a complex metabolic derangement including 